\title{
KEANEKARAGAMAN JENIS BAMBU DI DESA SARANG BURUNG KOLAM KECAMATAN JAWAI KABUPATEN SAMBAS
}

\author{
(Bamboo Species Diversity in the Sarang Burung Kolam Village Jawai District Sambas \\ Regency)
}

\author{
Jaidan, Evy Wardenaar, Gusti Eva Tavita \\ Fakultas Kehutanan Universitas Tanjungpura Jalan Daya Nasional, Pontianak 78124 \\ E-mail : Jaidanogol007@gmail.com
}

\begin{abstract}
Indonesia has 176 species of bamboo which constribute $16 \%$ of the world's bamboo species. $60 \%$ of bamboo grown in Indonesia is endemic bamboo. The purpose of this study was to record the diversity of bamboo species found in the Sarang Burung Kolam Village, Jawai District, Sambas Regency. The method used double plots laid out according to the presence of growing bamboo roaming with an observation plot area of $20 \mathrm{mx} 20 \mathrm{~m}$. Two different genera namely the genus Gigantochloa and Bambusa. Genus Bambusa consists of Bambusa vulgaris Schrad. Ex wendl, Bambusa vulgaris var. striata and Bambusa multiplex, Genus Gigantochloa consists of Gigantochloa balui and Gigantochloa atter). Type of bamboo that has the highest INP value is B. vulgaris Schrad. Ex wendl. (114.4599\%,) the medium INP value is G. atter (55.4006\%) and the lowest INP is B. vulgaris var.striata (3.2603\%). Species Diversity Index in Desa Sarang Burung Kolam, Jawai District, Sambas Regency is relatively low.
\end{abstract}

Keyword: Bamboo diversity, Sambas Regency, Sarang Burung Kolam Village.

\section{PENDAHULUAN}

Indonesia memiliki 176 spesies bambu yang merupakan $16 \%$ spesies bambu di dunia. Bambu yang tumbuh di Indonesia $60 \%$ merupakan bambu endemik (Widjaja, 2019). Bambu pada umumnya dapat dimanfaatkan oleh penduduk dan sangat berpotensi untuk dikembangkan. Bambu di Indonesia potensinya juga sangat menjanjikan untuk dimanfaatkan dengan baik, bambu merupakan tumbuhan mudah dikembangkan dan mempunyai daur hidup yang relatif cepat, dengan waktu panen 3-4 tahun. Bambu merupakan tumbuhan yang diharapkan dapat di jadikan sebagai substitusi bahan baku kayu komersial, karena kayu komersial semakin tahun produksinya semakin menurun dan harganya relatif mahal (Widjaja, 2019). Jawai merupakan sebuah Kecamatan di Kabupaten Sambas, Provinsi Kalimantan Barat yang memiliki wilayah seluas $270,40 \mathrm{Km}^{2}$ (27.040 Ha).

Penelitian tentang bambu di daerah Kecamatan Jawai terutama di Desa Sarang Burung Kolam masih belum ada yang meneliti tentang keanekaragaman jenis bambu. Oleh karena itu perlu dilakukan penelitian tentang keanekaragaman jenis bambu di Desa Sarang Burung Kolam Kecamatan Jawai Kabupaten Sambas. Tujuan penelitian ini adalah untuk mendata keanekaragaman jenis bambu yang terdapat di Desa Sarang Burung Kolam Kecamatan Jawai Kabupaten Sambas. 
Manfaat dari penelitian ini dapat memberikan informasi keanekaragaman jenis bambu yang terdapat di Desa Sarang Burung Kolam dan mengajak masyarakat untuk menjaga kelestariannya.

\section{METODE PENELITIAN}

Penelitian dilakukan di Desa Sarang Burung Kolam Kecamatan Jawai Kabupaten Sambas, lama penelitian 3 minggu di lapangan. Alat penelitian yaitu GPS, tali rapia, parang, meteran, tally sheet, phie-band, kamera digital, penggaris, buku identifikasi jenis-jenis di Jawa dan Bali (Widjaja 2001, 2005). Objek penelitian ini adalah semua jenis bambu yang ditemui di Desa Sarang Burung Kolam Kecamatan Jawai Kabupaten Sambas. Metode yang digunakan dalam penelitian ini adalah metode survei dengan menggunakan petak ganda yang diletakkan menurut keberadaan tumbuh bambu secara menjelajah dengan luas petak pengamatan $20 \mathrm{~m}$ x $20 \mathrm{~m}$, sebanyak 50 petak sehingga luas total pengamatan sebesar $2 \mathrm{Ha}$.

Pengumpulan Data

Data yang dikumpulkan dalam penelitian ini berupa data primer dan sekunder. Data primer meliputi semua jenis bambu yang ditemukan pada setiap petak pengamatan dan kemudian dianalisis yang meliputi bentuk: rumpun, percabangan, daun, bentuk kuping, ligula daun dari pelepah buluh; kuping, ligula dari pelepah daun, warna buluh, rebung, panjang ruas, diameter batang. Data sekunder ini berupa keadaan umum lokasi, literature, jurnal, peta lokasi, artikel.

Analisis Data

Pengolahan data hasil pengamatan dilakukan untuk mengetahui struktur dan komposisi jenis dengan melakukan analisis kerapatan, frekuensi dan dominansi jenis dan Indeks Nilai Penting (INP).

Indeks Nilai Penting

Menurut Fachrul (2008), indeks nilai penting dihitung dengan :

\section{Rumus : INP $=$ KR+FR}

Dimana :

INP = Indeks Nilai Penting

$\mathrm{KR}=$ Kerapatan Relatif

$\mathrm{FR}=$ Frekuensi Relatif

Nilai-nilai KR dan FR dapat dengan rumus sebagai berikut:

- Kerapatan Relatif (KR)

Kerapatan $=\frac{\text { Jumlah individu }}{\text { Luas petak pengamatan }}$

$\mathrm{KR}=\frac{\text { Kerapatan suatu jenis }}{\text { Kerapatan seluruh jenis }} \times \mathbf{1 0 0 \%}$

- Frekuensi Relatif (FR)

Frekuensi=

Jumlah petak ditemukan suatu jenis

Jumlah seluruh jenis

FR $=\frac{\text { Frekuensi suatu jenis }}{\text { Frekuensi seluruh jenis }} \times 100 \%$

Indeks Dominansi

Indeks dominansi digunakan untuk menentukan dominansi suatu jenis dalam suatu komunitas dengan menggunakan rumus sebagai berikut:

$\mathbf{C}=\sum\left(\frac{n i}{N}\right)^{2}$

Dimana :

$\mathrm{C}=$ indeks dominansi

$\mathrm{Ni}=$ jumlah individu dari spesies ke-I

$\mathrm{N}=$ jumlah keseluruhan dari individu 
Indeks keanekaragaman jenis

Keanekaragaman jenis adalah suatu indeks keanekaragaman secara keseluruhan dalam suatu tipe hutan yang dapat ditentukan dengan rumus Shannon-Wiener.

$\mathrm{H}^{\prime}=-\sum \frac{n i}{N} \log \frac{n i}{N}$

Dimana :

$\mathrm{H}^{\prime}=$ Indeks keanekaragaman ShannonWiener

$\mathrm{ni}=$ Jumlah individu dari suatu jenis ke-I

$\mathrm{N}=$ Jumlah total individu seluruh jenis

Kemerataan Jenis

Kemerataan jenis dapat dihitung dengan rumus sebagai berikut:

$\mathbf{E}=\frac{H^{\prime}}{\operatorname{In}(\boldsymbol{S})}$

Dimana:

$\mathrm{E}=$ Kemerataan jenis
$\mathrm{H}^{\prime}=$ indeks keanekaragaman shannon

$\mathrm{S}=$ jumlah jenis

$\mathrm{E}=0$ maka kemerataan jenisnya rendah, artinya kekayaan individu yang memiliki masing-masing spesies sangat jauh berbeda

$\mathrm{E}=1$, maka kemerataan antara spesies relatif merata atau jumlah individu masing-masing spesies relatif sama.

\section{HASIL DAN PEMBAHASAN}

\section{Keanekaragaman jenis bambu}

Berdasarkan hasil penelitian dan identifikasi lapangan yang telah dilaksanakan di Desa Sarang Burung Kolam Kecamatan Jawai Kabupaten Sambas ditemukan ada 5 jenis bambu dari 2 genus yang berbeda yaitu genus Gigantochloa dan Bambusa untuk lebih jelasnya dapat dilihat pada Tabel 1:

Tabel 1. Jenis dan Jumlah Bambu (Types and Amount of Bamboo)

\begin{tabular}{|c|c|c|c|c|c|c|}
\hline No & $\begin{array}{c}\text { Nama } \\
\text { Daerah }\end{array}$ & Nama latin & Genus & Petak & $\begin{array}{r}\text { Jumlah } \\
\text { Rumpun }\end{array}$ & Batang \\
\hline 1 & Aur & $\begin{array}{l}\text { Bambusa vulgaris Schrad. } \\
\text { Ex wendl }\end{array}$ & Bambusa & 28 & 47 & 1112 \\
\hline 2 & Aur kuning & $\begin{array}{l}\text { Bambusa vulgaris var. } \\
\text { striata }\end{array}$ & Bambusa & 1 & 1 & 5 \\
\hline 3 & Aur Salat & $\begin{array}{l}\text { Bambusa multipleks } \\
\text { (Lour.)Raeusch. Ex J.A. } \\
\text { \& J. H. Schult. }\end{array}$ & Bambusa & 3 & 8 & 734 \\
\hline 4 & Parring & $\begin{array}{l}\text { Gigantochloa } \\
\text { atter(Hassk.) Kurz }\end{array}$ & Gigantochloa & 14 & 22 & 516 \\
\hline 5 & Abek & $\begin{array}{l}\text { Gigantochloa balui K. M. } \\
\text { Wong }\end{array}$ & Gigantochloa & 3 & 4 & 280 \\
\hline
\end{tabular}

Adapun jenis yang ditemui sebagai berikut :

\section{1) Bambusa vulgaris Schrad. Ex wendl}

Diskripsi :

B. vulgaris Schrad. Ex wendl memiliki rumpun simpodial, tumbuh tegak dan tidak terlalu rapat, dengan tumbuhnya percabangan 1,5 $\mathrm{m}$ dari permukaan tanah,setiap ruas terdiri atas 2-5 cabang dengan satu cabang lebih besar dari pada cabang lainnya. Daun gundul dengan kuping pelepah buluh membulat dan 
tekeluk balik memiliki ligula daun dari pelepah buluh menggerigi, ligula dari pelepah daun rata yang berwarna hitam. Pelepah buluh mudah luruh, tertutup bulu hitam hingga coklat tua, buluh bambu berwarna hijau mengkilat, rebung bewarna hijau tertutup bulu

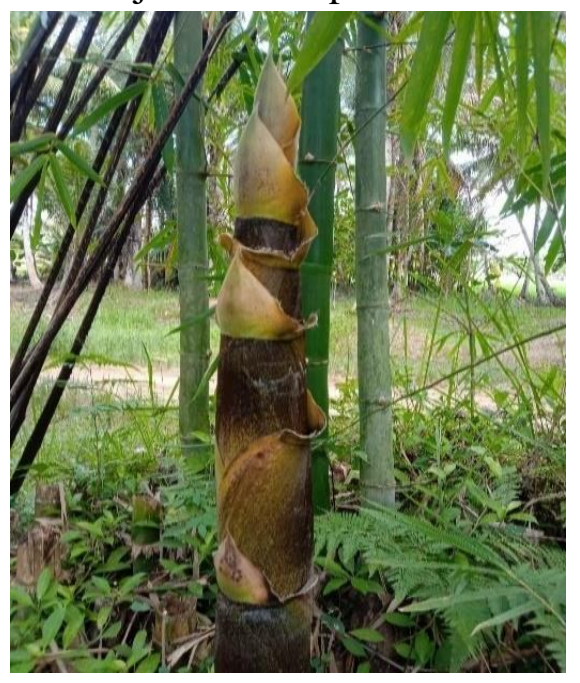

a. Rebung coklat hingga hitam. Panjang ruas 21-25 $\mathrm{cm}$, dengan diameter $6,5-8,5 \mathrm{~cm}$. Buluh bambu kuning tingginya mencapai 20 meter. Bambu ini biasa di manfaatkan oleh masyarakat sebagai bahan bangunan.

\section{Gambar 1. Bambu Aur (Aur Bamboo)}

\section{2) Bambusa vulgaris var. striata}

Diskripsi :

B. vulgaris var. striata memiliki rumpun simpodial, tumbuh tegak dan tidak terlalu rapat, dengan tumbuhnya percabangan $1,5 \mathrm{~m}$ dari permukaan tanah,setiap ruas terdiri atas 2-5 cabang dengan satu cabang lebih besar dari pada cabang lainnya. Daun gundul dengan kuping pelepah buluh membulat dan tekeluk balik memiliki ligula daun dari pelepah buluh menggerigi, ligula dari pelepah daun rata yang berwarna hitam. Pelepah buluh mudah luruh, tertutup bulu hitam hingga coklat tua, buluh bambu berwarna kuning bergaris-garis hijau, rebung bewarna hijau tertutup bulu coklat hingga hitam. Panjang ruas 20-25 cm, dengan diameter 6,5-7 cm. Buluh bambu kuning tingginya mencapai 20 meter. Bambu ini biasa di manfaatkan oleh masyarakat sebagai bahan bangunan. 


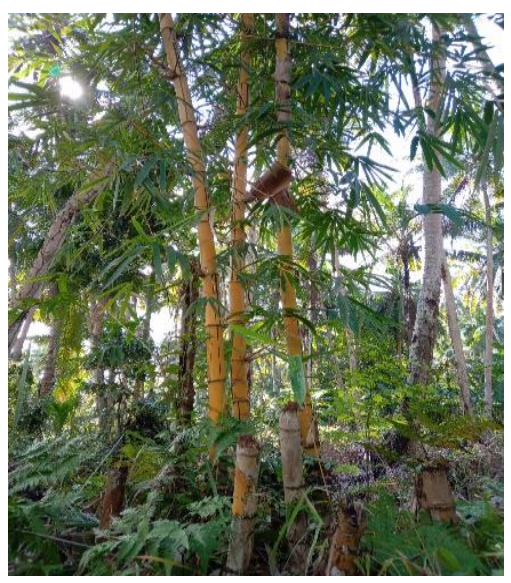

a. Rumpun

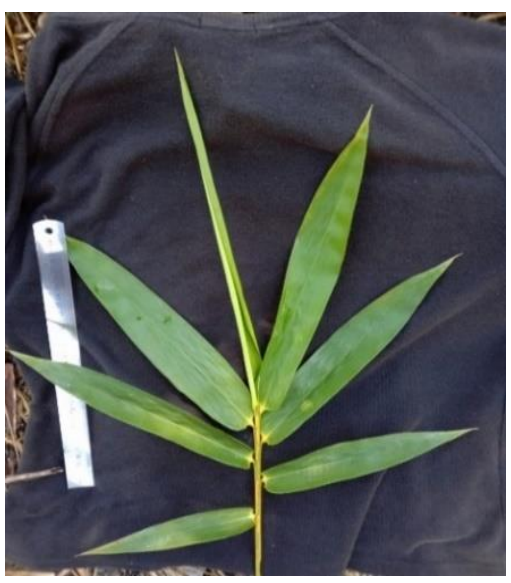

b. Daun

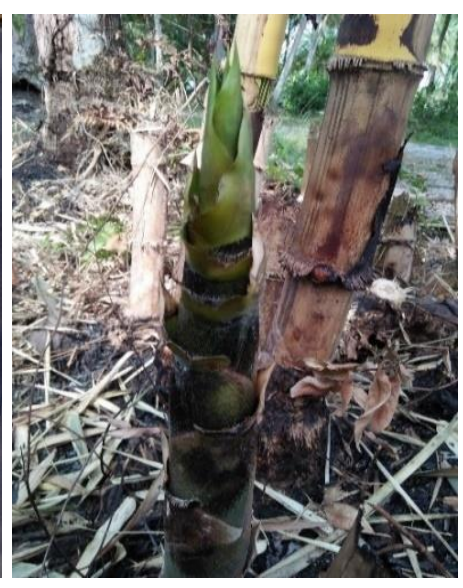

c. Rebung

\section{Gambar 2. Bambu Kuning (Yellow Bamboo)}

\section{3) Bambusa multipleks (Lour.)}

Raeusch. Ex J.A. \& J. H. Schult.

Diskripsi :

B. multipleks (Lour.)Raeusch. Ex J.A. \& J. H. Schult. Salat memiliki rumpun simpodial, rapat dan sangat padat. Percabangan terletak pada buku-buku dekat di permukaan tanah dan pada setiap percabangan terdiri atas $7-9 \mathrm{~cm}$ percabang yang besarnya hampir sama. Daun memita dengan permukaan belakang daun agak berbulu keputihputihan. Kuping pelepah buluh lurus menempel pada buluh dan hampir tidak

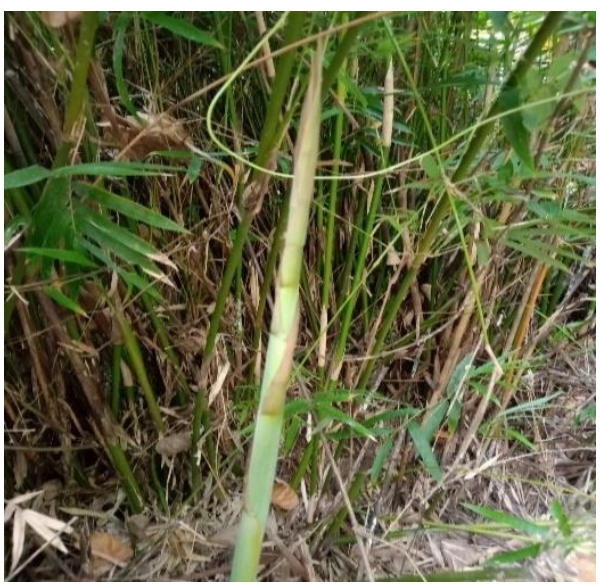

a. Rumpun dan Rebung tampak karena menyatu dengan pelepah. Ligula daun dari pelepah buluh menggerigi dan tidak teratur. Ligula pelepah daun kecil dengan bujur pendek. Buluh berwarna hijau, rebung yang berwarna hijau tidak mempunyai bulu atau gundul. Panjang ruas $41-52 \mathrm{~cm}$ dan diameter 1-1,5 cm. Buluh aor salat tegak dengan ujung melengkung ke bawah dan tinggi buluh 3-5 meter Buluh aur salat muda tertutup lapisan berwarna putih, tidak memiliki bulu atau gundul dan berwarna hijau Pelepah buluh mudah luruh tidak berbulu atau gundul.

Gambar 3. Bambu Aur Salat (Aur Salat Bamboo) 


\section{4) Gigantochloa atter (Hassk.) Kurz}

Diskripsi :

G. atter (Hassk.) Kurz memiliki rumpun yang simpodial, tegak lurus dan juga padat, dengan percabangan tumbuh jauh dari permukaan tanah, setiap cabang lateral memiliki salah satu cabang yang lebih besar dari cabang lainnya dan ujung yang melengkung. Daun parring gundul berwarna hijau, kuping pelepah buluh membulat dan ujung melengkung keluar, ligula daun dari pelepah buluh rata dan kecil, ligula daun dari pelepah daun rata. Buluh muda berwarna hijau dengan bulu berwarna hitam tersebar,

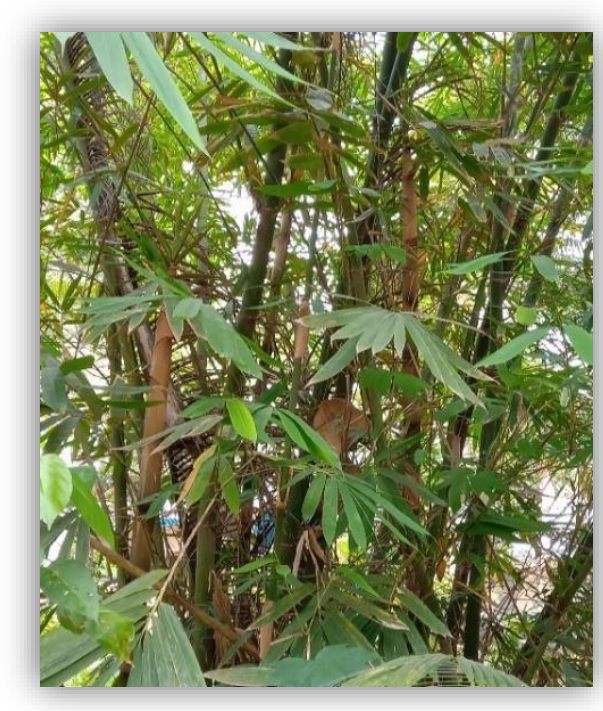

a. Rumpun jika sudah tua buluh gundul berwarna hijau hingga hijau tua, rebung parring berwarna hijau hingga keunguan yang tertutup bulu berwarna hitam. Buluh paring tingginya mencapai $15-20 \mathrm{~m}$ eter panjang ruas mencapai $33-36 \mathrm{~cm}$ dan diameter 3-7 cm dengan nodus yang berwarna coklat serta di bawah nodus ada seperti cincin lilin yang berwarna putih. Pelepah buluh tertutup bulu berwarna hitam dan mudah luruh saat dewasa atau tua, pelepah buluh juga memiliki kuping pelepah yang terkeluk balik dan membulat.

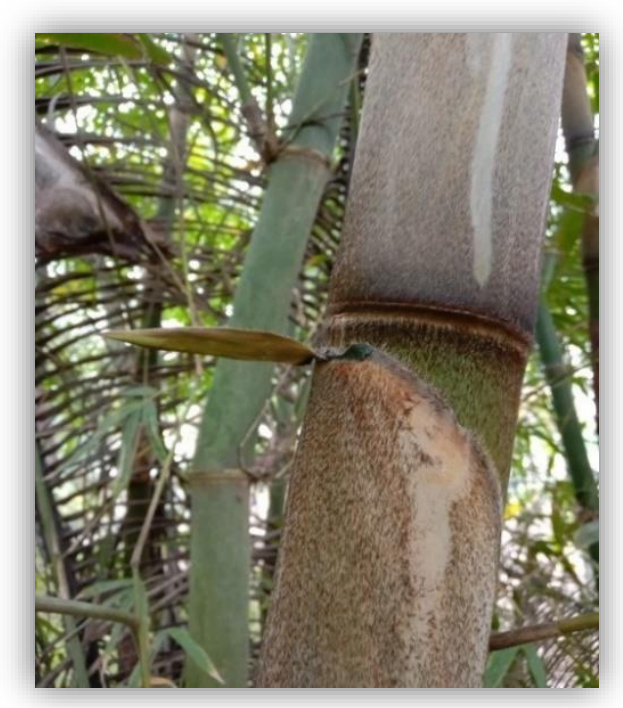

b. Pelepah

Gambar 4. Bambu Parring (Parring Bamboo)

\section{5) Gigantochloa balui K. M. Wong}

Diskripsi :

G. balui K. M. Wong merupakan tumbuhan rerumputan yang tumbuh baik di daerah tepian sungai dan daerah tropis yang lembab, abek memiliki rumpun yang simpodial padat dan juga tegak. Percabangan abek jauh dari permukaan tanah serta setiap cabang lateral memiliki satu cabang yang lebih besar dari pada cabang lainnya dengan ujung yang melengkung. Daun abek memiliki permukaan bagian bawah agak berbulu. Kuping pelepah buluh seperti bingkai serta terkeluk balik. Ligula daun dari pelepah buluh menggerigi. Ligula dari pelepah daun rata. Buluh abek berwarna hijau dengan bergaris-garis berwarna 
kuning di bagian bawah. Rebung abek berwarna hijau dengan garis garis kuning dan tertutup bulu putih. memiliki

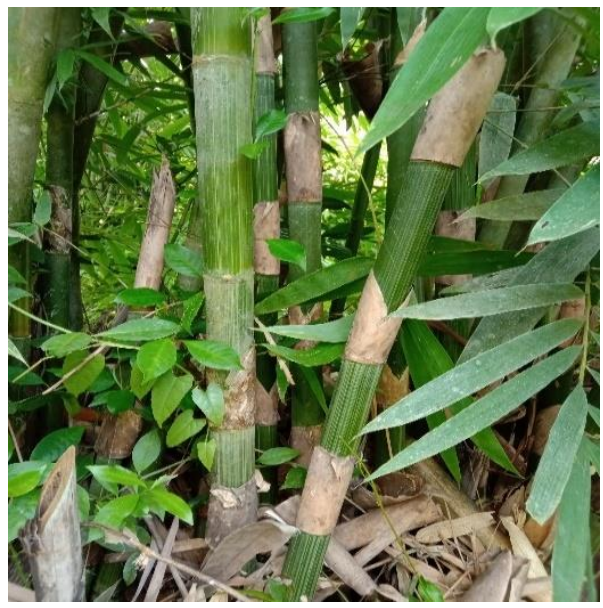

a. Batang panjang buluh 12-15 meter, panjang antar ruas $24-26 \mathrm{~cm}$ dan diameter 3,5-5,5 $\mathrm{cm}$.

Gambar 5. Bambu Abek (Abek Bamboo)

\section{Analisis Data Jenis-Jenis Bambu}

a. Indeks Nilai Penting (INP)

\section{Keanekaragaman Jenis Bambu}

Hasil perhitungan INP tiap jenis bambu yang ditemukan pada seluruh

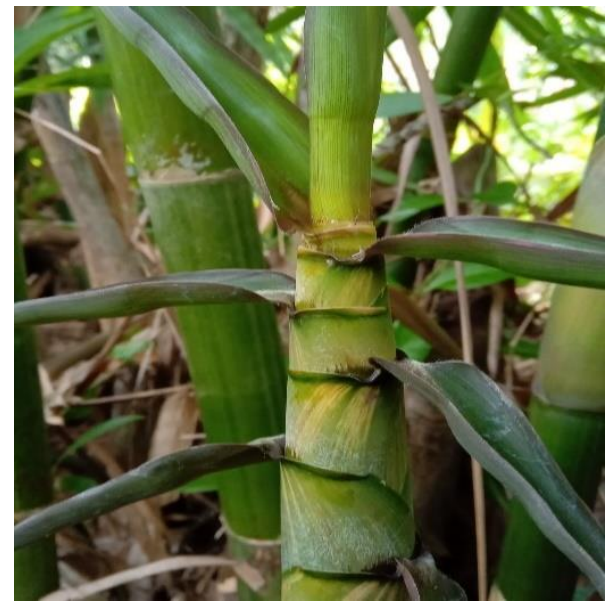

b. Rebung

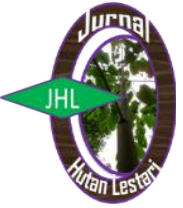


tertentu dan mempunyai toleransi yang tinggi sehingga, cocok dengan habitatnya.

\section{b. Indeks Dominansi Bambu}

Hasil analisis data untuk indeks dominasi jenis-jenis bambu yang

Tabel 3. Nilai Indeks Dominansi Jenis Bambu Yang Ditemukan Pada Seluruh Petak Pengamatan (The Dominance Index Value of Bamboo Species Found in All Observation Plots)

\begin{tabular}{lllc}
\hline No & Jenis Bambu & \multicolumn{1}{c}{ Nama Latin } & Indeks Dominansi \\
\hline 1 & Aur & Bambusa vulgaris Schrad. Ex wendl. & 0,3275 \\
2 & Aur kuning & Bambusa vulgaris var. striata & 0,0002 \\
3 & Aur Salat & $\begin{array}{l}\text { Bambusa multipleks (Lour.)Raeusch. } \\
\text { Ex J.A. \& J. H. Schult. }\end{array}$ & 0,0063 \\
& & Gigantochloa atter (Hassk.) Kurz & 0,0767 \\
4 & Parring & Gigantochloa balui K. M. Wong & 0,0030 \\
\hline 5 & Abek & & 0,0957 \\
\hline Rata-rata & & & \\
\hline
\end{tabular}

Berdasarkan hasil analisa data pada tabel 4 dari seluruh jenis bambu yang ada di Desa Sarang Burung Kolam Kecamatan Jawai Kabupaten Sambas, nilai yang tinggi dari lima jenis bambu adalah jenis bambu aur (B. vulgaris Schrad. Ex wendl) yaitu sebesar 0,3275, bambu parring dengan nilai 0,0797 dan yang terendah terdapat pada bambu kuning yaitu sebesar 0,0002. Berdasarkan nilai rata-rata dominansi yang di hitung sebesar 0,0827 yang berarti tidak terdapat jenis bambu yang mendominansi dari jenis bambu lainnya. Berdasarkan hasil penelitian Ridwansyah et al. (2015) diketahui nilai ditemukan di Desa Sarang Burung Kolam Kecamatan Jawai Kabupaten Sambas hasilnya dapat dilihat pada Tabel 3. 
Tabel 4. Nilai Indeks Keanekaragaman Jenis Bambu Pada Seluruh Petak Pengamatan (Bamboo Diversity Index Value of All Observation Plots)

\begin{tabular}{lllc}
\hline No & \multicolumn{1}{c}{ Jenis } & \multicolumn{1}{c}{ Nama Latin } & $\begin{array}{c}\text { Indeks } \\
\text { Kambu }\end{array}$ \\
& & & $\begin{array}{c}\text { Keanekaragaman } \\
\text { Jenis }\end{array}$ \\
\hline 1 & Aur & Bambusa vulgaris Schrad. Ex wendl. & 0,1387 \\
2 & Aur kuning & Bambusa vulgaris var. striata & 0,0029 \\
3 & Aur Salat & Bambusa multipleks (Lour.)Raeusch. & 0,0873 \\
& & Ex J.A. \& J. H. Schult. & 0,1544 \\
4 & Parring & Gigantochloa atter (Hassk.) Kurz & 0,0692 \\
\hline 5 & Abek & Gigantochloa balui K. M. Wong & 0,0957 \\
\hline Rata-rata & & & \\
\hline
\end{tabular}

Berdasarkan hasil analisis data seluruh jenis bambu di Desa Sarang Burung Kolam Kecamatan Jawai Kabupaten Sambas memiliki keanekaragaman yang rendah yaitu sebesar 0,0957 $\left(\mathrm{H}^{\prime}<1\right)$. Hal ini disebabkan oleh faktor lingkungan tempat tumbuhnya yang kurang mendukung. Berdasarkan hasil penelitian Isabella et al. (2017) memiliki keanekaragaman jenis yang rendah yaitu $\mathrm{H}^{\prime}=0,7848\left(\mathrm{H}^{\prime}<1\right)$ karena di Kawasan Hutan Air Terjun Riam Odong sedikitnya jenis bambu yang ditemukan pada kawasan tersebut. Menurut Odum 1993 dalam Fachrul (2008) keanekaragaman jenis dalam suatu kawasan dipengaruhi oleh dua faktor yaitu jumlah jenis dan banyaknya individu untuk semua jenis.

\section{d. Indeks Kemerataan Bambu}

Hasil perhitungan indeks kemerataan untuk tiap jenis bambu yang ditemukan pada seluruh petak pengamatan dan hasilnya dapat dilihat pada Tabel 5.

Tabel 5. Nilai Indeks Kemerataan Jenis Bambu yang Ditemukan Pada Seluruh Petak Pengamatan (Bamboo Index Evenness Index Value Found in All Observation Plots)

\begin{tabular}{lllc}
\hline No & \multicolumn{1}{c}{ Jenis } & \multicolumn{1}{c}{ Nama Latin } & $\begin{array}{c}\text { Indeks } \\
\text { Kemerataan }\end{array}$ \\
\hline 1 & Aur & Bambusa vulgaris Schrad. Ex wendl. & 0,0861 \\
2 & Aur kuning & Bambusa vulgaris var. striata & 0,0181 \\
3 & Aur Salat & Bambusa multipleks (Lour.)Raeusch. Ex & 0,0542 \\
& & J.A. \& J. H. Schult. & \\
4 & Parring & Gigantochloa atter (Hassk.) Kurz & 0,0959 \\
5 & Abek & Gigantochloa balui K. M. Wong & 0,0430 \\
\hline Rata-rata & & & 0,0595 \\
\hline
\end{tabular}


Berdasarkan hasil analisis data untuk indeks kemerataan jenis bambu yang ditemukan di Desa Sarang Burung Kolam Kecamatan Jawai Kabupaten Sambas adalah sebesar 0,0595(E=0), ini berarti memiliki kemerataan jenis yang rendah atau tidak merata. Berdasarkan hasil penelitian Isabella et al. (2017) di Kawasan Hutan Air Terjun Riam Odong Dusun Engkolai Kecamatan Jangkang Kabupaten Sanggau ditemukan 3 jenis bambu yang memiliki Indeks kemerataan jenis bambu dengan nilai rata-rata sebesar adalah 0,2455 yang berarti memiliki kemerataan jenis yang rendah atau tidak merata. Dilihat dari perbandingan memiliki persamaan indeks nilai kemerataan jenis yang rendah atau tidak merata karena kemerataan individu yang memiliki masing masing spesies sangat jauh berbeda.

Kemerataan jenis sangat rendah dapat disebabkan karena bambu bukan merupakan tumbuhan yang banyak di manfaatkan orang sehingga jarang di tanam dan adanya perbedaan habitat sehingga jenis yang ada tidak merata keberadaannya.

\section{Kesimpulan}

Berdasarkan hasil penelitian di Desa Sarang Burung Kolam Kecamatan Jawai Kabupaten Sambas ditemukan 5 jenis bambu yang terdiri dari 2 genus yaitu genus Bambusa dan genus Gigantochloa. Genus Bambusa yang terdiri dari $B$. vulgaris var.striata (Aur Kuning), $B$. vulgaris Schrad. Ex wendl (Aur) dan $B$. multiplex (Aur Sallat), sedangkan genus Gigantochloa terdiri dari $G$. balui (Abek) dan G. atter (Parring).
Jenis bambu yang memiliki nilai INP tertinggi adalah bambu aur (Bambusa vulgaris Schrad. Ex wendl.) dengan nilai INP 114,4599\% kemudian nilai INP sedang adalah jenis bambu parring( Gigantochloa atter) yaitu $55,4006 \%$ dan INP terendah adalah jenis bambu kuning (Bambusa vulgaris var.striata) yaitu 3,2603\%. Indeks Keanekaraganman Jenis di Desa Sarang Burung Kolam Kecamatan Jawai Kabupaten Sambas tergolong rendah. Dari 5 jenis bambu yang mendominansi adalah jenis bambu aur (Bambusa vulgaris Schrad. Ex wendl) sedangkan yang terendah adalah Bambusa vulgaris var.striata sedangkan nilai Indeks Kemerataan Jenis termasuk rendah atau tidak merata.

\section{Saran}

Berdasarkan hasil penelitian diketahui bahwa keanekaragaman jenis bambu di Desa Sarang Burung Kolam Kecamatan Jawai Kabupaten Sambas tergolong rendah, oleh karena itu perlu adanya upaya melestarikannya dan menjaga jenis bambu tersebut serta menghindari penebangan bambu yang berlebihan agar jenis yang ada tidak punah. Perlu diadakan penelitian lebih lanjut yaitu tentang pemanfaatan jenis bambu agar dapat mendapat informasi yang lebih lengkap.

\section{DAFTAR PUSTAKA}

Fachrul MF. 2008. Metode Sampling Bioekologi. PT Bumi Aksara. Jakarta. Hal. 198.

Isabella LL, Usman FH, Thamrin E. 2017. Keanekaragaman Jenis Bambu (Bambusodae) dalam Kawasan Hutan Air Terjun Riam 
JURNAL HUTAN LESTARI (2020)

Vol. 8 (2) : 249 - 259

Odong Dusun Engkolai

Kecamatan Jangkang Kabupaten

Sanggau. Jurnal Hutan Lestari.

Vol 5 (1): 88-94

Ridwansyah, Husni H, dan Wulandari RS. 2015. Keanekaragaman Jenis Banbu di Hutan Kota Kelurahan Buntut Kabupaten Sanggau. Fakultas Kehutanan Universitas Tanjungpura. Jurnal Hutan Lestari. Vol.3 (2): 199-297: Pontianak.

Widjaja EA. 2001. Identifikasi JenisJenis Bambu di Jawa. Bogor. Seri Panduan Lapangan. Bogor: Puslitbang Biologi LIPI.

Widjaja EA, Astuti P, Arinasa IBK, Sumatera IW. 2005. Identikit Bambu di Bali. Bidang Botani Pusat Penelitian Biologi- Lipi: Bogor.

Widjaja EA. 2019. The Spectacular of Indonesian Bamboos. Polagrade, Jakarta. P 188. 